\title{
COVID-19 awareness among undergraduates in a private university
}

\author{
Yi-Fan Tan, Lee-Yeng Ong, Meng-Chew Leow \\ Faculty of Information Science and Technology, Multimedia University, Melaka, Malaysia
}

\begin{abstract}
Article Info
Article history:

Received Jul 11, 2021

Revised Nov 8, 2021

Accepted Nov 20, 2021

\section{Keywords:}

Awareness level

Basic symptoms

COVID-19

Online survey

Undergraduates

ABSTRACT

Since the first declaration of the coronavirus disease 2019 (COVID-19) outbreak in December 2019, the pandemic has brought some significant lifestyle changes among the people across the globe. There might be some underestimation in the severity level of COVID-19 among younger people, specifically around the age group of undergraduates. This study evaluated the awareness level of Malaysian undergraduates towards COVID-19 in Malaysia via an online survey hosted in a COVID-19 awareness roadshow event. This study highlighted the importance of high awareness level of the pandemic among undergraduates and their impact towards managing the spread of the pandemic to the vulnerable population. The respondents were information technology (IT) undergraduates from Multimedia University Melaka Campus, Malaysia. The overall awareness level of the undergraduates is high. Most respondents had a clear understanding on the effects of personal hygiene and personal protective equipment to avoid getting infected with COVID-19, as well as where to go if they got infected with the coronavirus. Most respondents also showed decent knowledge in identifying the basic symptoms of COVID-19. These findings give an insight into the COVID-19 awareness level among undergraduates and may help the policymakers and university managements to control the spread of COVID-19 and other emerging infections.
\end{abstract}

This is an open access article under the CC BY-SA license.

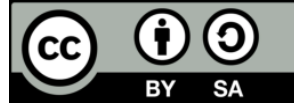

\section{Corresponding Author:}

Lee-Yeng Ong

Faculty of Information Science and Technology, Multimedia University

Jalan Ayer Keroh Lama, 75450 Melaka, Malaysia

Email: lyong@mmu.edu.my

\section{INTRODUCTION}

It has been one year since the official declaration of coronavirus disease 2019 (COVID-19) pandemic by the world health organization (WHO) [1]. As of September 4, 2021, the number of global confirmed deaths because of the pandemic has risen to over 4,553,811. In Malaysia, the pandemic has claimed the lives of over 17,521 citizens [2]. On the 25 of January 2020, the first case of COVID-19 was detected in Malaysia and was traced back to 3 Chinese nationals [3]. Roughly a week later, the first Malaysian that was infected with COVID-19 was confirmed. Since then, the number of reported COVID-19 cases grew steadily, until a religious event that took place at Sri Petaling, Kuala Lumpur, which spiked the total number of reported COVID-19 cases at an exponential rate. The Nation's Health Director, General Datuk Dr Noor Hisham Abdullah stated that 48\% of all COVID-19 cases in the nation that came after were linked to the religious event. The Prime Minister of Malaysia then announced a movement control order (MCO) as an effort to curb the spread of the pandemic. Although initially the countermeasures and policies were useful to contain the pandemic, which prompted the Malaysian government to ease restrictions under MCO, a local election in Sabah incidentally prompted the second wave of COVID-19 in Malaysia [4]. 
Fortunately, the vaccines for the virus have been developed and are distributed all over the globe to curb the pandemic as soon as possible. The vaccines that are available in Malaysia are BioNTech-Pfizer, CoronaVac, and Oxford-AstraZeneca. However, the vaccines are not immediately available for everyone and have to be given in phases [5]. On May 28, 2021, the Malaysian government announced that a total lockdown will be put in place in order to curb the recent resurgence of the coronavirus [6].

The pandemic itself brought some significant lifestyle changes and has caused psychological distress among the people [7], [8]. For undergraduates, the pandemic has put a halt to physical educational activities, which forces them to attend classes and lectures virtually. The awareness level of COVID-19 for undergraduates are important because the age group that undergraduates are in, which is around age 18-24 [9], engage themselves more in outgoing activities such as academic activities, sport clubs, part-time jobs, which put them in situations in which they will need to be in contact with others frequently. Study has also shown that being younger is among the factors that is associated with reluctance to abide by preventive protocols [10]. There is also a possibility that since young people are less likely to be hospitalized or have milder symptoms compared to older adults [11], there might be some underestimation in the severity level of COVID-19 among younger people, specifically around the age group of undergraduates. These aspects escalated the importance of analyzing the awareness level of COVID-19 among undergraduates in Malaysia. Having a rough idea about the COVID-19 awareness level of the undergraduates allows policies or countermeasures to be put in place not only for more effective COVID-19 prevention, while also avoiding other implications that are brought to them indirectly caused by the pandemic itself.

To the best of our knowledge, there is a survey that investigated the knowledge, attitudes and practice towards COVID-19 among Japanese university students [12], but the investigation on the importance of undergraduates having high COVID-19 awareness has not been done yet. The difference of awareness level in the pandemic among undergraduates may affect the tendency to maintain proper practices, which not only will affect the outcome of the pandemic but also affect undergraduates themselves in terms of personal health. Assessing the importance of high awareness level among Malaysian undergraduates might have a positive outcome in terms of introducing policies that can focus on keeping the awareness level of Malaysian undergraduates in check, which may help in public compliance to adhere to preventive measures and health practices prescribed by the authorities.

This study conducted an online survey in order to evaluate the basic understanding of COVID-19 pandemic among undergraduates in private university in Malaysia. This paper is organized as follows. The literature review section looks into existing studies that are related to the awareness level of university students and their findings. The methodology section explains the survey method that has been done in order to conduct the study. Results section is used to present the findings or statistics of the survey. The discussion section explains the outcomes of the survey and evaluates the awareness level of information technology undergraduates in Multimedia University Melaka Campus. Finally, the conclusion section comprises explanations of the limitations of the study and future works that can be conducted in order to access more insights regarding the relationship between undergraduates and COVID-19.

\section{LITERATURE REVIEW}

There are several reasons why high awareness levels among undergraduates are important to combat the pandemic. Hatabu et al. [12] conducted a survey to investigate the knowledge, attitudes, and practices (KAP) among university students in Japan and its associated factors. They found out that Japanese undergraduates have a relatively high level of awareness. However, their observation through logistic regressions and multiple linear regressions shows that there might be a decrease in self-restraint over time. A study on behavioral changes and preparedness of Japanese citizens against COVID-19 by Muto et al. [10] has shown that male under 30 are likely to be reluctant to implement proper prevention measures. In Malaysia, matriculation students were fined RM 1,500 for not wearing masks even though they had been confined within the college compound for over five months [13], which reveals the complacency among the students towards the pandemic over time. Having a high awareness level in the pandemic can help in reminding undergraduates to always abide by social distancing measures.

Although the age group that undergraduates are in might experience milder symptoms if infected by COVID-19 [11], having higher awareness in the pandemic knowledge may encourage undergraduates to abide to social distancing protocol more willingly, decreasing any chance of the spread of the pandemic even further. According to Zhao et al. [14], there is evidence showing that COVID-19 asymptomatic carriers can transmit the virus and have similar infectivity to COVID-19 patients experiencing expected symptoms. Jung et al. [15] analyzed the clinical characteristics of asymptomatic and symptomatic patients that are confirmed to be infected with COVID-19 in South Korea. Focusing on the 20-29 age groups specifically, most of the patients are asymptomatic patients at $62.6 \%$. This shows that undergraduates might unknowingly spread the pandemic even further without knowing the cause because typical COVID-19 symptoms might not 
show on them. Specifically, in Malaysia, undergraduates are expected to receive vaccines in May 2021 [5]. Undergraduates can also choose to apply for AstraZeneca vaccine that is offered by the Malaysian government on 'first come, first serve' basis in order to get vaccinated earlier [16]. While waiting for their turn to be vaccinated, social distancing efforts will still need to be maintained.

Introducing movement control order during the pandemic also encourages the public to stay at home, which spikes up the obesity rate because they are less active physically. Pell et al. [17] stated that the pattern of overweight and obesity in the 16-35 age group is alarming, in which the age group of undergraduates fits in perfectly. The centers for disease control (CDC) stated that people who are obese or overweight have an increased risk of severe illness caused by COVID-19 [18]. Therefore, it is important for undergraduates to have an awareness of the implications that COVID-19 might bring, specifically the ones with excess weight. The lack of outdoor activities while the pandemic is in place shifts the focus of maintaining a healthy lifestyle more heavily towards what can be done indoors.

Awareness in COVID-19 not only limits one from getting infected and spreading the pandemic, it is also a means to better manage the state of mental health among undergraduates. Through having significant awareness in COVID-19, undergraduates can understand exactly what to do or what to abide by in order to improve the current situation. Apart from death caused by the coronavirus directly, there is also the psychological impact that undergraduates have to face during the lockdown period. A study conducted by Eisenberg et al. [19] on a random sample of 4,000 college students reveals that $83 \%$ of the students experienced a decrease in academic performance and two-thirds of them are struggling with loneliness and the feeling of isolation which are caused by the impact of the pandemic on their mental health. It is also found that $39 \%$ of the students are experiencing a depression of some sort, whether it is major or moderate. Browning et al. [20] conducted a survey on psychological effects of COVID-19 among university students in the United States, which shows that undergraduates are having more psychological distress because of social distancing, cancelled school, and going out less. Evidence shows that undergraduates in China are facing more psychological distress, especially with their own finances, daily activities and delay in academic matters [21]. Relating to Malaysian undergraduates, Sundarasen et al. [22] conducted a survey on the psychological impact of COVID-19 and lockdown among university students in Malaysia. Their findings suggested that Malaysian university students do experience psychological distress by experiencing minimal all the way to extreme levels of anxiety because of financial constraints, remote online learning and uncertainty related to their academic performance and future career prospects. Undergraduates need to have an understanding of the impact that COVID-19 brings in terms of mental health. The CDC has proposed a guideline on mitigating anxiety levels, which includes several ways to not only maintain the undergraduate's own mental health but also to help others to cope with the mental burden that the pandemic causes [23].

The lack of awareness of the impact of the pandemic on undergraduates' mental health might cause multiple addiction issues. During extended periods of social isolation, undergraduates might opt for unhealthy stress reduction methods, such as substance misuse and social media addiction. Esmaeelzadeh et al. [24] conducted a study to examine the association between depression, anxiety and substance among Canadian post-secondary students. Through the study, they found out that there is a significant association between depression and tobacco and cannabis use. They also found out a gender-specific association between anxiety and female alcohol users.

According to Faust et al. [25], COVID-19 became a leading cause of death among younger adults in several regions in the United States. Faust et al. also stated that the total death among adults aged 20-49 in New York exceeds the state's usual leading cause of death, which includes drug overdoses and road accidents. Lechner et al. [26] studied the changes in alcohol use among undergraduates as a function of psychological distress and social support during and after campus closure at a university in Northeast Ohio. The authors found out that the students who endorsed using alcohol had shown increased alcohol consumption, especially for those who had symptoms of depression and anxiety. In terms of social media addiction, Islam et al. [27] conducted a study on problematic smartphone and social media use among Bangladeshi undergraduates during COVID-19. The authors found out that both problematic smartphone and social media use were linked to poor psychological well-being and are typically associated with other factors, such as poor sleep and lower age. The design of social media encourages endless scrolling and does not have a clear 'stop point', which is why it is so common for people to spend many hours online engaged with social media [28]. Thus, the change in lifestyle caused by COVID-19 can significantly affect one's mental health conditions, leading to increased depressive symptoms and addiction. Malaysian undergraduates are vulnerable to these issues as the COVID-19 situation in Malaysia continues to worsen. Hence, high awareness of side effects that COVID-19 brings is the key among undergraduates in order to identify and help the vulnerable ones by creating solidarity through empathize the difficulties faced and deep listening in order to offload the mental burden.

Int J Public Health Sci, Vol. 11, No. 1, March 2022: 28-37 


\section{RESEARCH METHOD}

\subsection{Study design, participants, and data collection}

This cross-sectional study administered a survey using a questionnaire constructed using Google Form. The participants involved were Multimedia University Melaka Campus Information Technology undergraduates. Because of the emergency and particular period, we adopted a convenience sampling, in which the respondents were informed by their respective lecturers to complete the survey. The survey form is distributed through a COVID-19 awareness campaign hosted on an online roadshow event, which is set out to increase COVID-19 awareness among undergraduates. The respondents will have to fill up the questionnaire before participating in the online roadshow event. Data were collected from December 30, 2020 to January 15, 2021.

\subsection{Questionnaire design}

The questionnaire was designed using an existing COVID-19 awareness. The questionnaire collects information such as the under-graduates' demographic data and their understanding regarding methods to curb the spread of COVID-19. Demographic information includes their name, email address, student ID, gender, and race. Table 1 shows the survey instrument used for this study. The first 4 questions inquire on the respondents' knowledge of effectiveness of hand hygiene, mask-wearing, gloves-wearing and antibiotics in curbing the spread of the virus. Respondents are required to answer "Yes", "No" or "Maybe" to these questions. After that, the respondents are also required to answer a checkbox question which they are required to select the correct symptoms of COVID-19 out of a list of random symptoms, which comprises cold, cough, sore throat, stomach ache, shortness of breath, fever, toothache, nausea, itching, diarrhea and redness in eye.

Table 1. Survey instrument

\begin{tabular}{ll}
\hline \multicolumn{1}{c}{ Question } & \multicolumn{1}{c}{ Answer selection } \\
\hline Is hand hygiene important in preventing the spread of the virus? & \\
Does wearing a mask help prevent the spread of the virus? & $\square$ Yes \\
Would wearing gloves help prevent the spread of the virus? & $\square$ No \\
Can COVID-19 be cured with antibiotics? & $\square$ Maybe \\
Do you know where to go if you start developing symptoms? & $\square$ Cold $\square$ Cough $\square$ Sore Throat $\square$ Stomach Ache $\square$ Fever \\
What are the main symptoms of the virus? & $\square$ Toothache $\square$ Nausea $\square$ Shortness of Breath \\
(Check all that apply) & $\square$ Itching $\square$ Diarrhea $\square$ Redness in eye \\
\hline
\end{tabular}

\subsection{Data pre-processing}

The data was separated by question through the use of Microsoft Excel 2013. Pre-processing for the 3-option (yes/no/maybe) questions ends here. However, the question which the users have to select the main symptoms was pre-processed differently. There are 11 correct options which can be reflected by selecting the 7 correct symptoms (cough, sore throat, shortness of breath, fever, nausea, diarrhea and redness in eye) and not selecting the 4 incorrect symptoms (cold, stomachache, toothache and itching). IBM statistical package for the social sciences (SPSS) statistics 26 was used to do frequency analysis and descriptive analysis for the different questions, respectively.

\subsection{Frequency analysis}

The 3-option questions were analyzed using this method. This is to visualize the percentages of each type of response among all the answers given by the respondents. Pie charts were used in order to visualize the data itself. The awareness level of the respondents was determined by judging the choice of answer that has the highest percentage for each of the questions.

\subsection{Descriptive statistics}

The checkbox question was analyzed using descriptive statistics. This is to summarize the data given by the respondent in order to determine the respondents' understanding of the symptoms of COVID19. The range of the correct and incorrect options selected will help determine the difference in the understanding of COVID-19 symptoms among the respondents with the most and least awareness level. As the wider the range, there will be the bigger the difference in knowledge of COVID-19 symptoms among the respondents. The average score can give a rough estimate of the level of understanding of COVID-19 symptoms. As the higher the average scores, the higher the level of understanding of COVID-19 symptoms among the respondents. The standard deviation can help to better visualize the difference of understanding from one respondent to another. The higher the standard deviation score obtained, the larger the difference in understanding from one respondent to another. 


\section{RESULTS AND DISCUSSION}

\subsection{Frequency analysis for yes/no/maybe questions}

Table 2 shows the frequency analysis for the 3-option question with the visual representation in Figure 1 to 5. Based on the results showed in Table 2, most of the participants have decent knowledge and awareness of COVID-19 prevention and cure. Majority $(94.5 \%)$ of the participants agree that hand hygiene is important in preventing the spread of the virus, signaling that the participants have good knowledge in importance of hygiene in curbing the spread of the pandemic. Majority of the participants $(94.5 \%)$ think that wearing a mask would help in preventing the spread of the virus, which shows that the participants have good knowledge on how a mask can help in preventing the spread of the virus. A sizable number of participants at $61.8 \%$ think that wearing gloves would help prevent the spread of the virus. The decisions of the participants are not as clear cut as the questions mentioned earlier. There are $60 \%$ of the participants think that COVID-19 cannot be cured with antibiotics, with over a third of them not being sure about the effect of antibiotics against the virus. Lastly, $85.5 \%$ of the participants know where to get help if COVID-19 symptoms develop. This shows that the undergraduates clearly understand the place that they should go in order to seek help if they think they are suspiciously infected.

Table 2. Frequency analysis for yes/no/maybe questions

\begin{tabular}{lccc}
\hline \multicolumn{1}{c}{ Question } & \multicolumn{3}{c}{ Answer distribution (\%) } \\
& Yes & No & Maybe \\
\hline Is hand hygiene important in preventing the spread of the virus? & 94.5 & 0.0 & 5.5 \\
Does wearing a mask help prevent the spread of the virus? & 94.5 & 0.0 & 5.5 \\
Would wearing gloves help prevent the spread of the virus? & 61.8 & 9.1 & 29.1 \\
Can COVID-19 be cured with antibiotics? & 5.5 & 60.0 & 34.5 \\
Do you know where to go if you start developing symptoms? & 85.5 & 5.5 & 9.1 \\
\hline
\end{tabular}

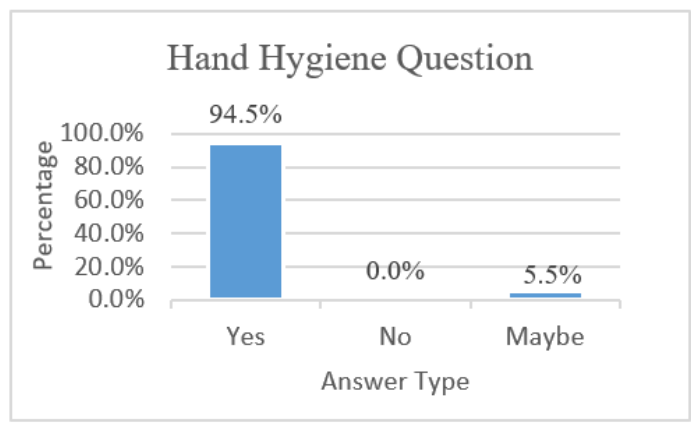

Figure 1. Distribution of hand hygiene question

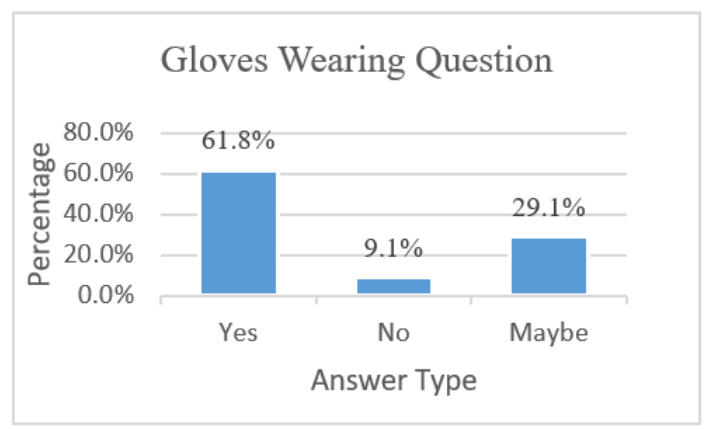

Figure 3. Distribution of gloves wearing question

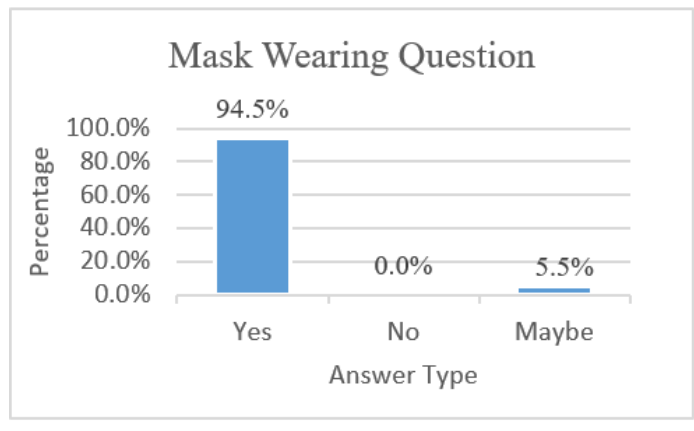

Figure 2. Distribution of mask wearing question

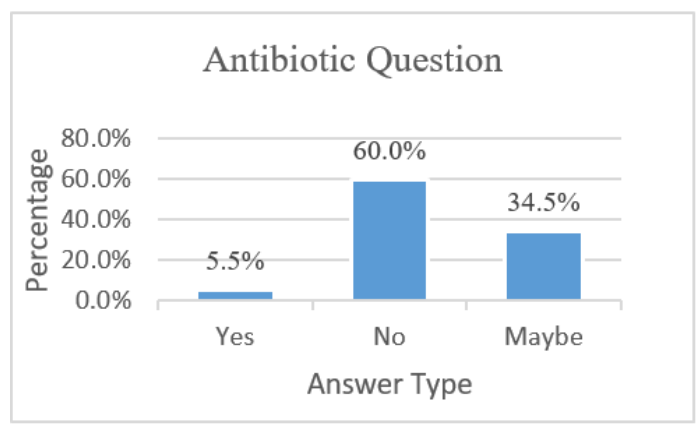

Figure 4. Distribution of antibiotic question

\subsection{Descriptive analysis for symptoms-selection question}

Table 3 shows the descriptive analysis for the symptoms-selection question. Based on Table 3, it is observed that the respondents could get 6 out of 11 correct answers at the minimum based on the combination of symptoms that they selected. The maximum correct answers selected is at 10 out of 11 , which 
means the respondents either selected a wrong symptom, or left out a correct symptom in their symptom combination. The respondents selected 1 wrong answer at the minimum and 5 wrong answers at the maximum. The average total for total correct answer and total wrong answer is at 8 and 3, respectively. Most respondents selected 8 correct answers and 3 wrong answers, as shown in Figures 6 and 7. Each respondent deviates around 0.923. This shows that most of the respondents can identify the correct and incorrect symptoms of COVID-19 most of the time, with the minority being confused with the actual symptoms that the coronavirus causes.

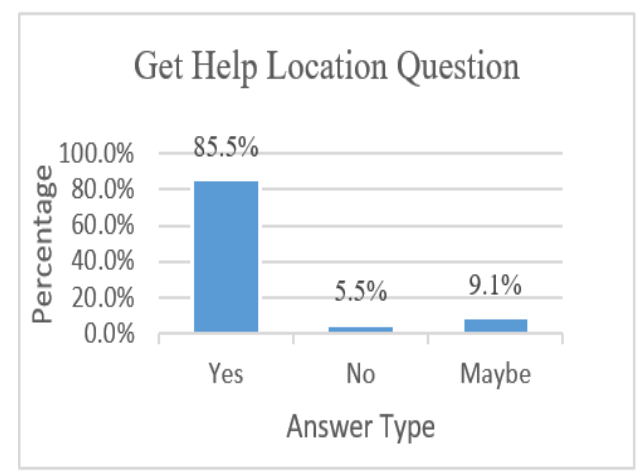

Figure 5. Distribution of get help location question

Table 3. Symptoms-selection question descriptive statistics

\begin{tabular}{ccccc}
\hline Question & Min. & Max. & Mean & Std. deviation \\
\hline Total correct answer & 6 & 10 & 8.00 & 0.923 \\
Total wrong answer & 1 & 5 & 3.00 & 0.923 \\
\hline
\end{tabular}

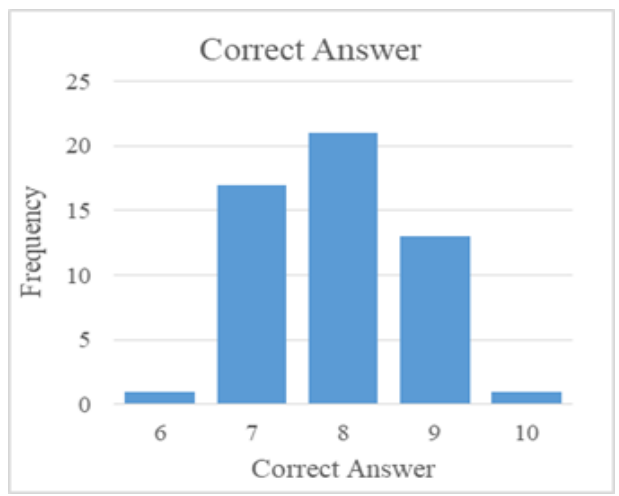

Figure 6. Bar chart for correct answers

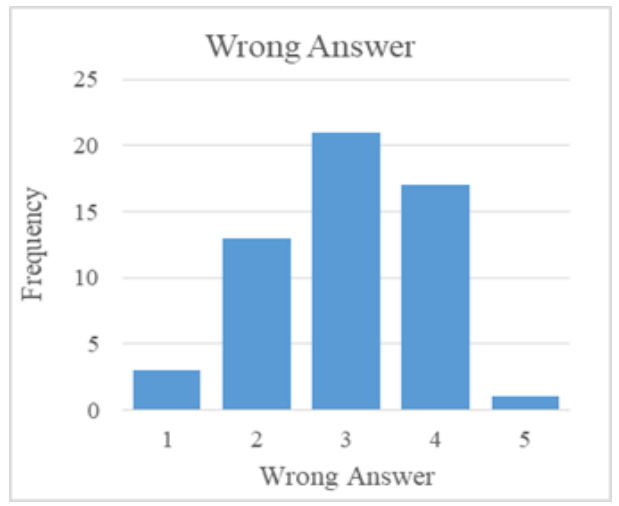

Figure 7. Bar chart for wrong answers 


\subsection{Discussion}

Undergraduates in Multimedia University belong to a representative group of the young generation and the outbreak of the COVID-19 pandemic has affected their daily lives and activities, not to mention the typical university life that they expect to experience themselves. Awareness of COVID-19 among undergraduates is important because it will affect their knowledge and attitude towards the pandemic. Without adequate awareness of the pandemic, they might be easily swayed by the spreading of fake news in social media. Having low awareness level in the symptoms of COVID-19 amongst undergraduates might also develop a misunderstanding towards the infectivity of COVID-19 since they will only suffer from mild symptoms if infected with the said virus compared to the other age group [11]. Such mindset might also lead to a decrease in self-restraint over time, as concluded by Hatabu et al. [12] and Muto et al. [10]. The lack of awareness towards the pandemic may cause the virus to be spread even further without knowing the signs and symptoms of COVID-19. This may worsen the situation of the pandemic itself in Malaysia. The public, specifically the one with the same age group as undergraduates, might subconsciously ignore the protocol in place without actually knowing the significance and purpose of the preventive measure itself.

Most of the respondents seem to have good knowledge of the effect of hand hygiene and mask wearing on preventing the spread of the pandemic. According to the CDC, mask wearing and hand washing are one step in order to prevent getting sick from the coronavirus [29]. The respondents showed some hesitancy when answering the question on gloves wearing, which shows that they might not have adequate knowledge on the effect of gloves to prevent the spread of the pandemic. CDC states that glove wearing is unnecessary in most situations unless it is for cleaning and disinfecting a certain location or caring for someone who is sick. For day-to-day activities, such as buying groceries at the nearest mall, gloves may still lead to the spread of germs. This is further backed up by Yadav et al. [30] where the authors stated that gloves may provide a new surface for a virus to live. This shows that adequate information in gloves wearing must be put into any kind of attempt to increase awareness of COVID-19 among the public.

Although the results of the survey look promising so far towards the awareness of COVID-19 among undergraduates, the fact that Multimedia University Melaka Campus undergraduates lack basic knowledge of antibiotics cannot be ignored. There are a sizable number of respondents who think antibiotics are effective in curing COVID-19. Antibiotics are only needed when certain infections are caused by bacteria [31], which will not work on COVID-19 since it is caused by a virus. Incorrect usage of antibiotics [32] will cause antibiotic resistance, which occurs when bacteria change in response to the use of these medicines. Jairoun et al. [33] found that university students have a high rate of antibiotic self-medication, in which the researcher prompts an effective and comprehensive antibiotic-stewardship program is needed as a part of undergraduate education. The misinformation regarding antibiotics effect against COVID-19 during the pandemic may worsen the situation where the public would panic buy medication, causing drug shortages as stated by Bookwalter [34], which may cause the medication to be less accessible to the ones that needs the prescription most.

Most of the respondents have a clear idea of where to go if COVID-19 symptoms develop in them. According to the CDC [35], in order to prevent any potential spread of the virus, anyone that has developed mild COVID-19 symptoms should be isolated at the place that they are currently staying since they can recover at home without medical care. Besides staying isolated, the infected should let close contacts know that they may have been exposed to COVID-19, which can help to prevent the pandemic from continuing to spread by having close contacts voluntarily self-isolate at home. However, if the infected are experiencing severe symptoms, they will need to seek emergency medical care immediately by contacting the local healthcare provider for further instructions. If the infected have a medical appointment that cannot be postponed, it is important to call the doctor's office before visiting so that proper prevention procedures can be carried out to allow for visits from the infected.

For the symptoms selection questions, most of the respondents selected around 7 to 9 correct answers, with a few outliers at 6 and 10 correct answers. Majority of the respondents also selected around 2 to 4 wrong answers, with 1 and 5 as outliers. This suggests that the respondents have a decent knowledge of COVID-19 symptoms overall. The outliers might be caused by the respondents assuming COVID-19 could cause the incorrect symptoms to develop after one has been infected with the coronavirus, as well as the confusion because these symptoms are like the symptoms of common illness. There might also be a possibility of the respondents influenced by fake news, which causes the outliers in the data. Basic understanding of COVID-19 symptoms is of utmost importance for undergraduates during the pandemic. Mild COVID-19 symptoms that they might experience [11] can be easily dismissed by them if there is a clear lack of awareness in the pandemic, which can cause them to spread the virus even further subconsciously as an asymptomatic carrier [14], [15]. Having basic understanding of COVID-19 symptoms can help to exercise extreme caution in outdoor activity during the pandemic, whether it is to get basic supplies or buy food. If

Int J Public Health Sci, Vol. 11, No. 1, March 2022: 28-37 
they find themselves suspiciously infected with coronavirus, they could opt for other methods to fulfil their daily routine such as opting for delivery services for food and groceries as well as exercising at home.

Overall, the information technology undergraduates in Multimedia University Melaka Campus have a decent level of awareness of the aspect of precaution measures and basic knowledge against COVID-19. The respondents showed a good understanding of the importance of hygiene practices and personal protective equipment to prevent themselves from being infected and spreading the coronavirus even further. It is important to recognize that high awareness level of COVID-19 is paramount during the pandemic and failing to do so may trigger a ripple effect, which will affect other aspects of life among undergraduates such as their physical and mental health. The goal of having a high awareness level in the pandemic is to make sure one does not get infected and spread the virus even further. Without high awareness level, undergraduates might accidentally repeat the same mistake that might cost them their physical health by getting infected with COVID-19. Unbeknownst to the undergraduates, they may subconsciously spread the virus among close contacts wherever they go. The public, including undergraduates, will probably experience feelings of despair and hopelessness because of prolonged periods of lockdown, which will have a toll on their physical and mental health by picking up unhealthy eating habits as well as seeking addictions for stress relief. These effects stemmed from the feeling of loneliness present and the lack of social activities among undergraduates [19], [20], financial difficulties, as well as being unsure of their future because of unimproved COVID-19 situation in Malaysia [21], [22], which all could be originated from the lack of awareness in the pandemic among undergraduates themselves.

\section{CONCLUSION}

Overall, Malaysian undergraduates possess a good understanding of the basic knowledge and preventive steps towards COVID-19. The findings in this study are useful to inform policymakers and health authorities to understand the unique position of undergraduates during this pandemic, as well as the potential effects that undergraduates could bring if high awareness level towards COVID-19 is present, or lack thereof. Maintaining or improving the current awareness among Malaysian undergraduates towards the pandemic is of utmost importance. Since the lack of awareness in COVID-19 among them may not only cause the highlighted group of people to face difficulty in terms of their personal health and future outlook, it may also undermine the authorities' previous effort to control the spread of COVID-19 not only among undergraduates but also the Malaysian society.

This study has certain limitations. First, since it mainly adopts a convenience sampling method, the samples were limited in number. The results may not sufficiently represent undergraduates entirely. The survey instrument could be more comprehensive, which may include the state of mental health among undergraduates and also their knowledge towards COVID-19 vaccines, which can add another dimension to evaluate their awareness level. Furthermore, the results obtained from this study are time-dependent. As the COVID-19 situation is changing rapidly with the introduction of the vaccine for the pandemic, the results obtained here may or may not be informational for policy making or countermeasure planning.

\section{ACKNOWLEDGEMENTS}

This research was funded by Telekom Malaysia Research \& Development; grant number RDTC/191001 (MMUE/190086).

\section{REFERENCES}

[1] World Health Organization, "WHO Director-General's opening remarks at the media briefing on COVID-19," World Health Organization, Mar. 2020.

[2] Coronavirus Resource Center, “COVID-19 map - Johns Hopkins Coronavirus Resource Center,” Johns Hopkins University \& Medicine, 2021. https://coronavirus.jhu.edu/map.html (accessed Sep. 04, 2021).

[3] Elengoe Asita, "COVID-19 outbreak in Malaysia," Osong Public Health Res Perspect, vol. 11, no. 3, pp. 93-100, 2020, doi: 10.24171/j.phrp.2020.11.3.08.

[4] S. S. Yong and J. K.-M. Sia, "COVID-19 and social wellbeing in Malaysia: a case study," Current Psychology, Sep. 2021, doi: 10.1007/s12144-021-02290-6.

[5] The Special Committee For Ensuring Access To COVID-19 Vaccine Supply, "National COVID-19 immunisation programm," Ministry of Foreign Affairs, Malaysia, p. 16, Feb. 2021.

[6] V. Babulal, "Malaysia goes under full lockdown again from tuesday," New Straits Times, Mar. 2021. https://www.nst.com.my/news/nation/2021/05/694006/malaysia-goes-under-full-lockdown-again-Tuesday (accessed Jun. 22, 2021).

[7] L. M. Nelson et al., "US public concerns about the COVID-19 pandemic from Results of a Survey Given via Social Media," JAMA Internal Medicine, vol. 180, no. 7, pp. 1020-1022, Apr. 2020, doi: 10.1001/jamainternmed.2020.1369.

[8] J. Qiu, B. Shen, M. Zhao, Z. Wang, B. Xie, and Y. Xu, "A nationwide survey of psychological distress among Chinese people in the COVID-19 epidemic: implications and policy recommendations," General psychiatry, vol. 33, no. 2, pp. e100213-e100213, Mar. 2020, doi: 10.1136/gpsych-2020-100213. 
[9] D. W. Schanzenbach, L. Bauer, and A. Breitwieser, "Eight Economic Facts on Higher Education," Apr. 2017. https://www.brookings.edu/wp-content/uploads/2017/04/thp_20170426_eight_economic_facts_higher_education.pdf (accessed Jun. 22, 2021).

[10] K. Muto, I. Yamamoto, M. Nagasu, M. Tanaka, and K. Wada, “Japanese citizens' behavioral changes and preparedness against COVID-19: An online survey during the early phase of the pandemic," PLOS ONE, vol. 15, no. 6, pp. 1-18, Jun. 2020, doi: 10.1371/journal.pone.0234292.

[11] L. L. Maragakis, "Coronavirus and COVID-19: younger adults are at risk, too," Dec. 2020. https://www.hopkinsmedicine.org/health/conditions-and-diseases/coronavirus/coronavirus-and-covid-19-younger-adults-are-atrisk-too (accessed Jun 22, 2021).

[12] A. Hatabu et al., "Knowledge, attitudes, and practices toward COVID-19 among university students in Japan and associated factors: An online cross-sectional survey," PLOS ONE, vol. 15, no. 12, p. e0244350, Dec. 2020, doi: 10.1371/journal.pone.0244350.

[13] Z. M. Arif, "Probe underway after matriculation students fined RM1,500 while in campus," New Straits Times, Apr. 2021. https://www.nst.com.my/news/nation/2021/04/683734/probe-underway-after-matriculation-students-fined-rm1500-while-campus (accessed Jun. 22, 2021).

[14] H. Zhao, X. Lu, Y. Deng, Y. Tang, and J. Lu, "COVID-19: asymptomatic carrier transmission is an underestimated problem," Epidemiology and Infection, vol. 148, Jun. 2020, doi: 10.1017/S0950268820001235.

[15] C.-Y. Jung, H. Park, D. W. Kim, Y. J. Choi, S. W. Kim, and T. I. Chang, "Clinical characteristics of asymptomatic patients with COVID-19: a nationwide Cohort Study in South Korea," International Journal of Infectious Diseases, vol. 99, pp. 266-268, Oct. 2020, doi: 10.1016/j.ijid.2020.08.001.

[16] J. Khaos, "Khairy: Malaysia to offer AstraZeneca vaccine on 'first come, first served' basis," The Star, Apr. 2021. https://www.thestar.com.my/news/nation/2021/04/28/khairy-malaysia-to-offer-astrazeneca-vaccine-on-039first-come-firstserve039-basis (accessed Jun. 22, 2021).

[17] C. Pell et al., "Coming of age, becoming obese: a cross-sectional analysis of obesity among adolescents and young adults in Malaysia," BMC Public Health, vol. 16, no. 1, Dec. 2016, doi: 10.1186/s12889-016-3746-x.

[18] CDC, "Obesity, race/ethnicity, and COVID-19," Centers for Disease Control and Prevention, Mar. 2021. https://www.cdc.gov/obesity/downloads/data/obesity-maps/obesity-race-ethnicity-and-COVID-19-h.pdf (accessed Jun. 23, 2021).

[19] D. Eisenberg, S. K. Lipson, J. Heinze, S. Zhou, P. Schulz, and L. Li, "The Healthy Minds Study - Fall 2020 Data Report," 2020. https://healthymindsnetwork.org/wp-content/uploads/2021/02/HMS-Fall-2020-National-Data-Report.pdf (accessed Jun. 22, 2021).

[20] M. H. E. M. Browning et al., "Psychological impacts from COVID-19 among university students: Risk factors across seven states in the United States," PLOS ONE, vol. 16, no. 1, pp. 1-27, Jan. 2021, doi: 10.1371/journal.pone.0245327.

[21] W. Cao et al., "The psychological impact of the COVID-19 epidemic on college students in China," Psychiatry Research, vol. 287, May 2020, doi: 10.1016/j.psychres.2020.112934.

[22] S. Sundarasen et al., "Psychological Impact of COVID-19 and lockdown among University Students in Malaysia: Implications and Policy Recommendations," International Journal of Environmental Research and Public Health, vol. 17, no. 17, pp. 1-13, Aug. 2020, doi: 10.3390/ijerph17176206.

[23] CDC, "Mental Health and Coping During COVID-19," Centers for Disease Control and Prevention, Jan. 2021. https://www.cdc.gov/coronavirus/2019-ncov/daily-life-coping/managing-stress-anxiety.html (accessed Jun. 23, 2021).

[24] S. Esmaeelzadeh, J. Moraros, L. Thorpe, and Y. Bird, "The association between depression, anxiety and substance use among Canadian post-secondary students," Neuropsychiatric Disease and Treatment, vol. 14, pp. 3241-3251, Nov. 2018, doi: 10.2147/NDT.S187419.

[25] J. S. Faust et al., "All-cause excess mortality and COVID-19-related mortality among us adults aged 25-44 years, March-July 2020," JAMA, vol. 325, no. 8, Feb. 2021, doi: 10.1001/jama.2020.24243.

[26] W. V Lechner, K. R. Laurene, S. Patel, M. Anderson, C. Grega, and D. R. Kenne, "Changes in alcohol use as a function of psychological distress and social support following COVID-19 related University closings," Addictive Behaviors, vol. 110, Nov. 2020, doi: 10.1016/j.addbeh.2020.106527.

[27] M. S. Islam et al., "Problematic smartphone and social media use among Bangladeshi College and University Students Amid COVID-19: the role of psychological well-being and pandemic related factors," Frontiers in Psychiatry, vol. 12, pp. 1-12, Apr. 2021, doi: 10.3389/fpsyt.2021.647386.

[28] D. R. Garfin, "Technology as a coping tool during the coronavirus disease 2019 (COVID-19) pandemic: Implications and recommendations," Stress and Health, vol. 36, no. 4, pp. 555-559, Oct. 2020, doi: 10.1002/smi.2975.

[29] CDC, "How to protect yourself \& others," Centers for Disease Control and Prevention, Jun. 2021. https://www.cdc.gov/coronavirus/2019-ncov/prevent-getting-sick/prevention.html (accessed Jun. 23, 2021).

[30] D. K. Yadav, P. K. Shah, S. P. Shah, and A. K. Yadav, "The use of disposable gloves by general public during COVID-19 increases the risk of cross-contamination," Asia Pacific Journal of Public Health, vol. 32, no. 5, pp. 289-291, Jul. 2020, doi: $10.1177 / 1010539520932704$.

[31] CDC, "Be antibiotics aware: smart use, best care," Centers for Disease Control and Prevention, Nov. 2020. https://www.cdc.gov/patientsafety/features/be-antibiotics-aware.html (accessed Jun. 23, 2021).

[32] WHO, "Antibiotic resistance," World Health Organization, Jul. 2020. https://www.who.int/news-room/factsheets/detail/antibiotic-resistance (accessed Jun. 23, 2021).

[33] A. Jairoun, N. Hassan, A. Ali, O. Jairoun, M. Shahwan, and M. Hassali, "University students' knowledge, attitudes, and practice regarding antibiotic use and associated factors: a cross-sectional study in the United Arab Emirates," International journal of general medicine, vol. 12, pp. 235-246, Jun. 2019, doi: 10.2147/IJGM.S200641.

[34] C. M. Bookwalter, "Drug shortages amid the COVID-19 pandemic," US Pharmacist, vol. 46, no. 2, pp. 25-28, Feb. 2021.

[35] CDC, "What to Do If You Are Sick," Centers for Disease Control and Prevention, Mar. 2021. https://www.cdc.gov/coronavirus/2019-ncov/if-you-are-sick/steps-when-sick.html (accessed Jun. 23, 2021). 


\section{BIOGRAPHIES OF AUTHORS}

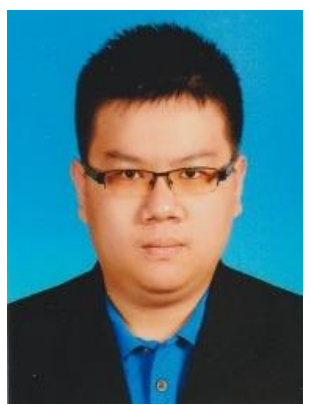

Yi-Fan Tan (D) SC SC P is a full time Research Assistant at Multimedia University. Yi-Fan Tan received a Bachelor's degree of Computer Science in the major of artificial intelligence from Multimedia University. His research focuses on the multitude of impacts that is brought by the COVID-19 pandemic towards the people. He can be contacted at email: tanyifan0405@gmail.com.

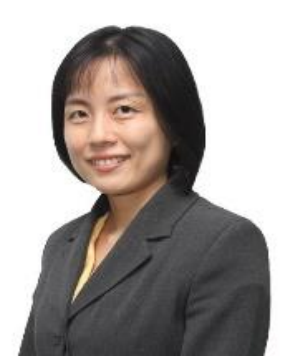

Lee-Yeng Ong (iD 8D SC P obtained her Master of Engineering Science and Doctor of Philosophy from Multimedia University. With more than 10 years of teaching and research experiences in the academic field of information technology (IT), she currently serves as a lecturer for artificial intelligence (AI) major in Faculty of Information Science \& Technology (FIST), Multimedia University. Her research interests include computer vision, image processing, data science and video surveillance systems. She can be contacted at email: lyong@mmu.edu.my.

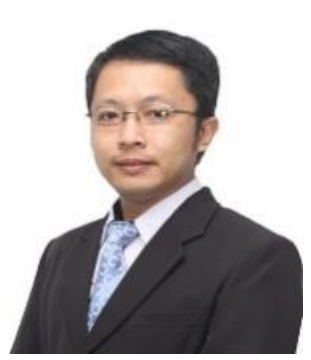

Meng-Chew Leow (iD) SAl SC P obtained his Doctor of Philosophy from Multimedia University. His research interest is in game-based learning, specifically in role-playing gamebased learning. He is also interested in system science, practical spirituality, and philosophy. He can be contacted at email: mcleow@mmu.edu.my. 